\title{
Drinking Water Treatment at Home: a Trial in Dhaka, Bangladesh
}

\author{
N. A. Molla ${ }^{a, b *}$, K. A. Mollah ${ }^{b}$, A. Hossain ${ }^{a}$, O. Shipinc, H. P. Nur ${ }^{a}$ I. Nimmi ${ }^{a}$ and A. Aminul ${ }^{a}$ \\ ${ }^{a}$ Bangladesh Council of Scientific and Industrial Research Laboratories, Dr. Qudrat-I-Khuda Road, Dhanmondi \\ Dhaka-1205, Bangladesh, ${ }^{b}$ University of Yamanashi, Japan, ' Asian Institute of Technology, Thailand.
}

\begin{abstract}
The pilot trial on Aquatabs ${ }^{\mathrm{TM}}$ disinfectant tablets was undertaken over a period of one month (three 10-day period excluding the pre- and post-trial activities) during October-December 2004 in an area of low-income urban communities suffering from a lack of basic health services including a lack of adequate and safe water and sanitation facilities (Lalbagh) as well as adjacent areas of old Dhaka. Drinking water consumed by 347 persons was treated in 50 households comprising 70 children under 5 years old. A pre-trial survey and testing of the water supplies demonstrated that the mean faecal coliform count was $>10^{3} \mathrm{MPN} / 100 \mathrm{~mL}$ and that all children (100\%) belonged to a "Severe Diarrhoea Group" (> 3 incidences of light diarrhoea or any serious diarrhoeal condition). One effervescent Aquatabs ${ }^{\text {TM }}$ (67mg sodium dichloroisocyanurate) was added by the mother to the local container (filled from a community tap or standpipe, often through an illegal connection), which held about 20-25 litres of unsafe water, giving a dosage of about $2 \mathrm{mg} / \mathrm{L}$ free chlorine. During the trial period water samples were tested at 3 x 10-day period for free residual chlorine levels and faecal coliform counts at all households. About $65.7 \%$ of children were reported to be free from diarrhoea during the trial period, there was a strong association between "under-chlorinated" water $(<0.5 \mathrm{mg} / \mathrm{L}$ residual free chlorine) and reported diarrhoea incidences. Survey analysis during the pilot trial concluded that $70 \%$ of mothers were not aware that health improvements were related to water supply and sanitation.
\end{abstract}

Keywords: Aquatabs ${ }^{\mathrm{TM}}$, Diarrhoea, Low income urban community.

\section{Introduction}

A large proportion of the World's people do not have access to improved or microbiologically safe sources of water for drinking and other essential purposes. Diarrhoea is a disease of the gastrointestinal tract caused by the ingestion of the bacteria, viruses that are spread via contaminated water and/or food. Human feces carry huge quantities of these bacteria, viruses and when shed in turn contaminates the water supply. Diarrhoea usually occurs in conditions of extreme poverty, where inadequate or non-existent water and sanitation facilities result in poor physical hygiene (Hemson, 2001).WHO/UNICEF estimated that 1.1 billion people do not have access to "improved drinking-water sources". Consumption of unsafe water continues to be one of the major causes of the 2.2 million diarrhoeal disease deaths occurring annually, mostly in children (WHO/UNICEF, 2000). There is now conclusive evidence that simple, acceptable, low-cost interventions at the household and community level are capable of dramatically improving the microbial quality of household stored water and reducing the attendant risks of diarrhoeal disease and death. Many different water collection and storage systems and strategies have been developed to produce drinking water of acceptable microbi- ological quality able to reduce diarrhoeal and other waterborne diseases among user households and communities in developed and developing countries (UNICEF 2001).

Where water-borne disease is a problem, then Aquatabs ${ }^{\mathrm{TM}}$ has been proven to be an effective solution for producing safe drinking water. Aquatabs ${ }^{\mathrm{TM}}$ have been tried and tested in a wide range of natural and polluted water sources. Aquatabs $^{\mathrm{TM}}$ are rapidly dissolving, effervescent tablets which deliver an accurately known and measurable dose of free available chlorine, recommended for the disinfection of small volumes of water at the "point of consumption". They range in sizes to suite different applications and are used in accordance with emergency relief or daily consumption requirements (Medentech 2004). Diarrhoea takes a heavy toll in Bangladesh, which is criss-crossed by waterways and routinely ravaged by floods, cyclones and droughts. The majority of patients are children from the lowest social strata. Eighty percent of patients attending hospitals are less than 5 years of age, more than half of these have moderate to severe malnutrition, while $60 \%$ of their mothers are illiterate and $50 \%$ have a household monthly income of less than US\$

*Corresponding Author, Email: neella2274@yahoo.com 
50. Each year some 20 million children suffer an average of 3.5 episodes of diarrhoea and diarrhoea takes epidemic form during flood periods every year (Mustafa 2008). Most of the people do not have any idea of the detrimental effects of untreated or unsafe drinking water and why diarrhoea occurs. Socio-cultural status of populations in Bangladesh necessitates the need to introduce effective and easily applicable products to combat the problem. The low-income urban people always suffer the most from lack of safe drinking water and a shortage of safe water to be used domestically. The study investigated the issues related to drinking water supply in the low-income urban community of Lalbagh area in Dhaka, Bangladesh. The objectives of this study were: 1) To examine the practicability of motivating mothers to utilize Aquatabs ${ }^{\mathrm{TM}}$ disinfecting tablets for a significant period of time; 2) To find out the correct dosages; 3) To examine the social, cultural and aesthetic acceptability of the Aquatabs ${ }^{\mathrm{TM}}$ chlorinated water; 4) To evaluate the success of chlorinated water in reducing water borne disease (diarrhoea etc.), particularly in infants under 5 years old; 5) Endeavour to investigate the feasibility of bringing about behavioral changes in use of drinking water.

\section{Materials and Methods}

\section{Selection of the study area}

Dhaka, the capital city of Bangladesh was targeted study area. The selection of the study area was based on the community having no access to safe drinking water, use of unsafe drinking water sources, the presence of a child under 5 years old, ethical aspects of using new techniques etc. Dhaka is the densely populated area in Bangladesh where the poor and low-income people, such as daily labourers, garments and industry workers, rickshaw-pullers etc., live in highly inappropriate conditions. Reasons for selecting Lalbagh area was that the water was more polluted than in the other two preliminary investigated areas. Moreover 50 households had agreed to use Aquatabs ${ }^{\mathrm{TM}}$ for their household drinking water purification. In this area suspected levels of diarrhoea were considered a problem with the majority of patients being children under 5 years of age. This was later confirmed. Moreover, in Lalbagh area, same findings were also demonstrated by Mollah et al. (2009a).

\section{Sampling methods}

The study units were households having at least one child under 5 years old permanent resident. Households were qualified for inclusion in the study if the sole water source was untreated and significantly contaminated with faecal coli forms bacteria. Contamination was verified by performing bacteriological tests on a sample of the household water at the scheduled visit (faecal coli forms test). All households had been visited by the Study Investigator who explained the purpose of the study and invited their participation. It was clearly explained to the households that the purpose of the trial was to purify drinking water which entailed dissolving tablets in all water to be consumed orally and used for hygiene purposes, the tablets were to be kept safely and not swallowed directly. These instructions were verified at each 10-day period of the follow-up work. A sample of the household's water had been tested to ascertain the chlorine dosage requirement. The correct number of tablets to be added to the water container was calculated and a label was attached to the container showing the number of tablets to be added. Correct dosage of tablets was assumed to be 1 tablet (weight: $67 \mathrm{mg}$ NaDCC) per 20-25 L of water (household container) to produce a Free Residual Chlorine concentration of 0.5$5 \mathrm{mg} / \mathrm{L}$ at all times. Members of the household had been given samples of the Aquatabs ${ }^{\mathrm{TM}}$-treated water to drink and, if they agreed to take part in the study, the Investigator advised and monitored the woman/mother responsible for water, while she added the Aquatabs ${ }^{\mathrm{TM}}$. The name of each child under 5 in the household was recorded and a history and frequency of recent diarrhoea was noted down. Each participating household had been visited once in a 10-day period for three subsequent periods (1 month overall) by the study investigator. The investigator verified that the household water was treated with Aquatabs ${ }^{\mathrm{TM}}$ correctly by testing for residual chlorine levels and ensured that the person adding the tablets knew what to do. The free residual chlorine content was noted down after being analyzed at the laboratory. If necessary, the procedures were explained again. The APHA method (MPN method) was used to measure the faecal coli forms contamination of the water. At each 10-day period visit the occurrence of diarrhoea was also recorded for each child with the length and duration of each episode (Mollah et al. 2009b). Households that dropped out of the study were categorized and recorded along with the reasons for doing so.

\section{Data analysis}

Both the qualitative and quantitative analyses were done based on a questionnaire survey, informal interviews, observations and tests. The following endpoints were analyzed: i) Proportion of households whose water was: a) under-chlorinated (Free Residual Chlorine $<0.5 \mathrm{mg} / \mathrm{L}$ ), b) correctly chlorinated (Free Residual Chlorine $0.5-5.0 \mathrm{mg} / \mathrm{L}$ ), analyses were done for each 10-day period visit; ii) Bacterial levels in each household water for each 10-day period visit; iii) Reasons for non-compliance or drop-out of families from the study; iv) The household's opinion of Aquatabs ${ }^{\mathrm{TM}}$ : whether they noticed/disliked/liked the taste; whether they noticed any 
effects on health; whether they would be willing to continue to add the tablets in the future. v) The relationship between successful addition of Aquatabs ${ }^{\mathrm{TM}}$ and incidence of diarrhoea. The critical parameters of water quality were: a) number of faecal coli form (or E. coli) in any 100mL sample, b) a minimum free residual chlorine of $0.5 \mathrm{mg} / \mathrm{L}$ and maximum 5mg/L recommended after 30 minutes contact time, c) $\mathrm{pH}<8.0$ and d) turbidity $<5$ NTU. As per the instructions of the study investigator the responsible person (family guide, usually mother) of each household had written the dosages (how many tablets added, i.e. one tablet per 20-25 liters drinking water which should produce roughly $2 \mathrm{mg} / \mathrm{L}$ Free Residual Chlorine) on the drinking water storage pot (but sometimes they did not follow instructions). There was also some error during sample collection.

\section{Results and Discussion}

Socio-economic profile and water supply and sanitation situation in the study area

The $5.74 \mathrm{sq} \mathrm{km}$ study area, Lalbahg thana area is one of the 27 sub-districts of Dhaka. 71,000 households with a population of 365,323 live in this area which belongs to the old part of the Dhaka City Corporation. Administratively Lalbagh Thana consists of 9 wards, 116 mouzas and 11 villages (BBS 2002). Total population of respondents in the 50 households was 347. In the study area, majority of the household heads are males and the result of the survey indicates that most of the mothers are illiterate. About 54\% mothers have no formal education. The situation of water supply is one of the worst in the area. Dhaka Water supply and Sewerage Authority (DWASA) is the organization primarily responsible for water supply of Dhaka city. The quality of the water supply service of DWASA is very poor. It was observed during this study that safe water supply is not getting priority at household level, as well as at the government level. In the Lalbagh area, there is one government hospital, one private hospital and four clinics. According to the respondent mothers interviewed by the study investigator their children have suffered from diarrhoea throughout the whole year and on average, nearly $85 \%$ of the children suffered from some kind of disease during past 30 days. Significance of study of children under 5 years in the context of diarrheal diseases, health status observed in this study was morbidity patterns with children under 5 years old, because at this age they are particularly vulnerable to diseases. The total number of 5 years old children in the study area was 70. Diarrhoea is the most common illness (52.5\%) and has the highest prevalence, similar tendency that was found in other study by Mollah et al. (2009b). In study area, the sanitation situation is in a very poor condition. The people in this area have sanitary pit latrines but only at the rate of one latrine per 15-20 households and these are unhygienic (DPHE 2003). One tap is commonly used for all sanitary purposes, for all domestic chores and for drinking water. But the major problem is that children under 5 rarely use latrines. Most of the mothers let their child defecate in casual places outside, both day and night. When the field survey was undertaken to review the mothers' perception of sanitary latrines and their children's defecation habits, 85\% mothers did not know that latrines

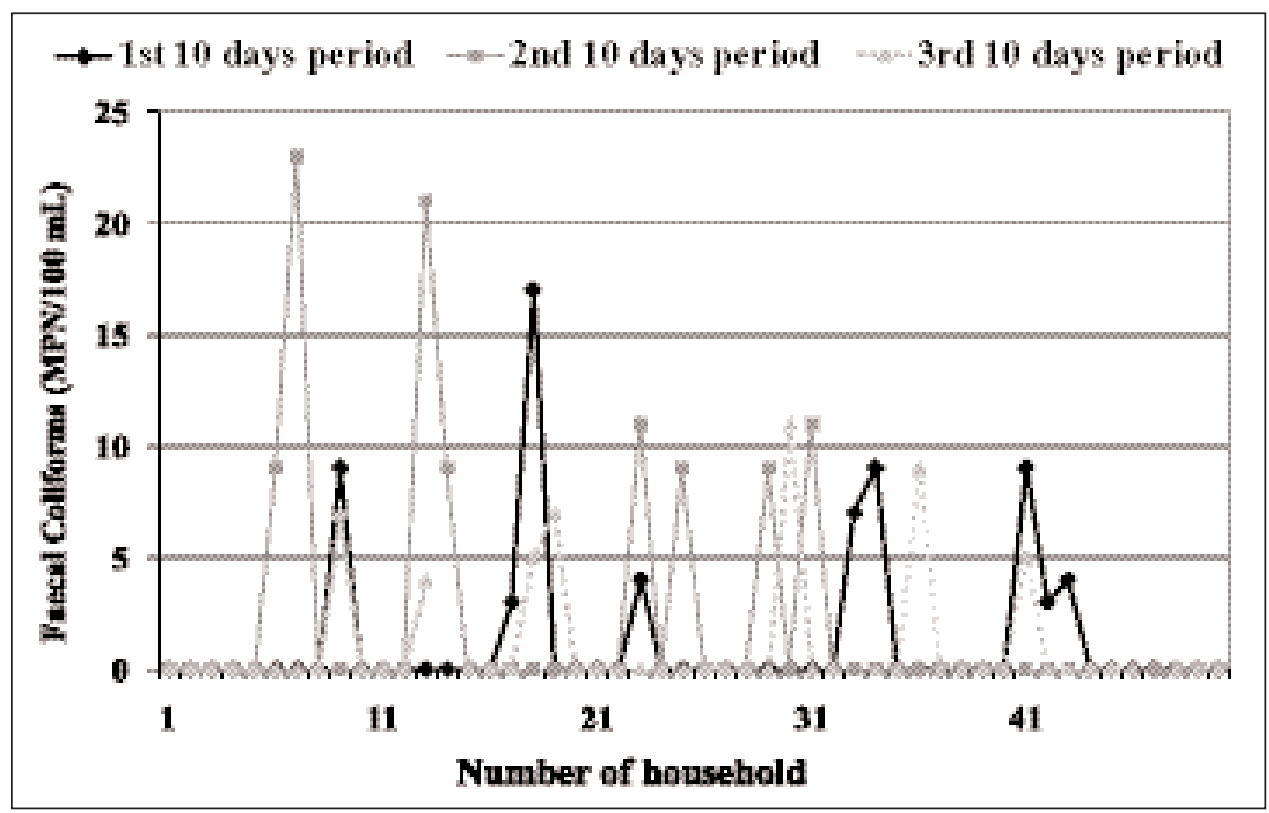

Fig. 1. 10-day period comparison of faecal coli forms in surveyed household water in the study area. 
prevent pollution of the environment and prevent the spread of bacteria and related diarrhoea, and other water-borne diseases. Three houses were dropped-out from this study at the end of the 3rd 10-day period.

Presentation of the results of the Aquatabs ${ }^{\text {TM }}$ Trial in the Lalbagh study area

After a one month period of observation on the families using Aquatabs ${ }^{\mathrm{TM}}$ in the Lalbagh area, Water samples at the 50 investigated households (70 children under 5 years old) were taken during this study to control purification of drinking water by using Aquatabs ${ }^{\mathrm{TM}}$. Two parameters (Faecal Coli forms and Free Residual Chlorine) were chosen and tested for water quality analysis. The study site was affected by flood one month before this research investigation.

\section{Observations on Faecal Coli forms in household water (bacteriological analysis)}

Ideally a drinking water should be free of faecal coli form. Fig. 1 shows the levels of faecal coli forms at each 10-day period visit. Most of the households were free from faecal coli forms except for a few. In the 1st 10-day period 9 household (18\%), in the 2nd 10-day period 8 household (16\%) and in the 3rd 10-day period 7 household (15\%) water samples were found faecally contaminated, even after being treated with Aquatabs $^{\mathrm{TM}}$. The results show that faecal coli form counts had a pre-trial mean level of $>103 \mathrm{MPN} / 100 \mathrm{~mL}$ in the Lalbagh area. Within the 50 households of the study, the mean faecal coli form counts were 1.3 MPN/100mL in the 1st 10-day period of the trial, $2.04 \mathrm{MPN} / 100 \mathrm{~mL}$ in the 2 nd 10-day period and1.02 MPN/100mL in the 3rd 10-day period. In the 1st 10-day period 41 households (82\%), in the 2nd 10-day period 42 households (84\%) and in the 3rd 10- day period 40 households (85\%) were free from faecal coli forms. The maximum faecal coli form level was found to be $23 \mathrm{MPN} / 100 \mathrm{~mL}$. There was a possibility that this may have been caused by secondary contamination through handling.

Observations on free residual chlorine levels in household water

Figure 2 shows free residual chlorine comparison. It is found from the graph that free residual chlorine (FRC) is fluctuating in almost all households in every 10-day period, whereas faecal coli forms were not found to fluctuate in almost every household.

\section{Observations on under-chlorinated water in household water}

After one month of using Aquatabs ${ }^{\mathrm{TM}}$ for purification of drinking water in the study area it was observed that underchlorinated water was found in the households distributed as shown in figure 3 . It is obvious that 2 households had underchlorinated water at the end of the 1st 10-day period, 8 households at the end of the 2nd 10-day period and 5 households at the end of the 3rd 10-day period.

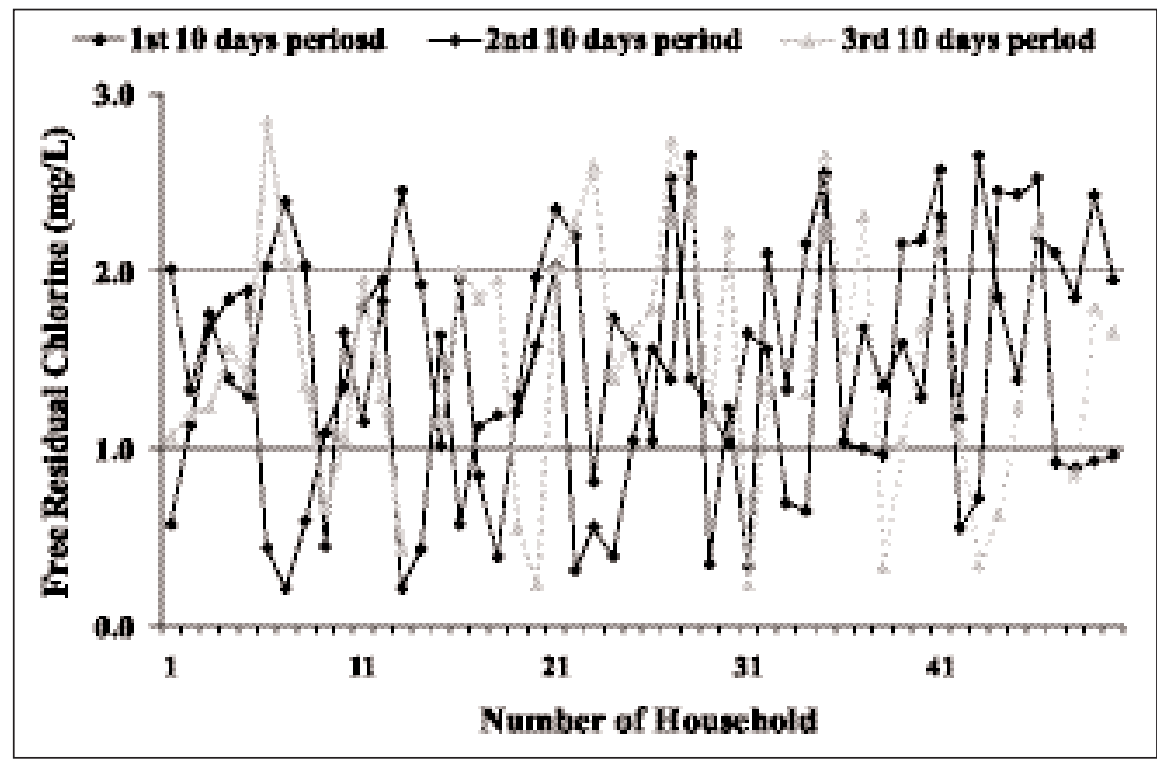

Fig. 2. 10-day period comparison of free residual chlorine in surveyed household water in the study area. 


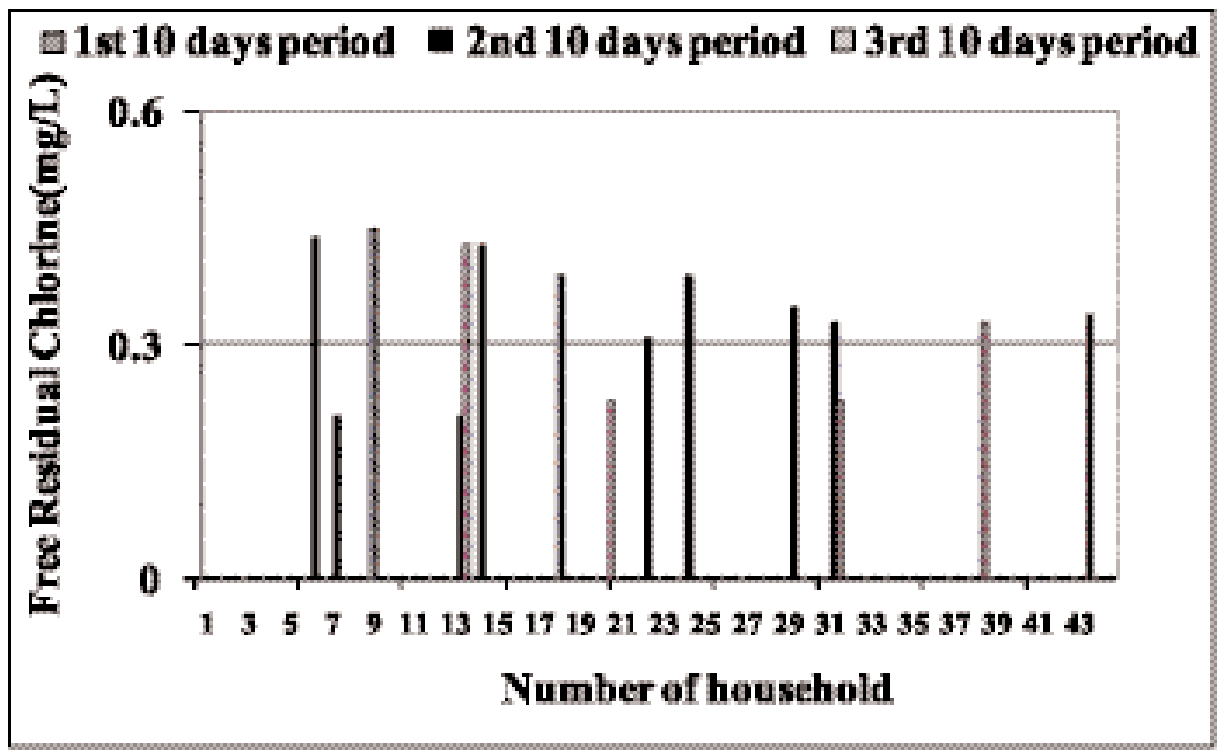

Fig. 3. 10-day period comparison of under chlorination in surveyed household water in the study area.

Observations on correctly chlorinated water in household water

After one month of using Aquatabs ${ }^{\mathrm{TM}}$ for purification of drinking water in the study area, it was observed that water, which was correctly chlorinated, was distributed among households as shown in Figure 4.
Throughout the trial no household had over-chlorinated their water in any period. In the 1st 10-day period 96\% households $(n=50)$ had correctly chlorinated their water ( $>0.5 \mathrm{mg} / \mathrm{l}-<5 \mathrm{mg} / \mathrm{L}$ free residual chlorine), in the 2nd 10-day period $84 \%$ households $(n=50)$ had correctly chlorinated their water and in the 3rd 10-day period 89\% households $(n=47)$ had correctly chlorinated their water. Where the

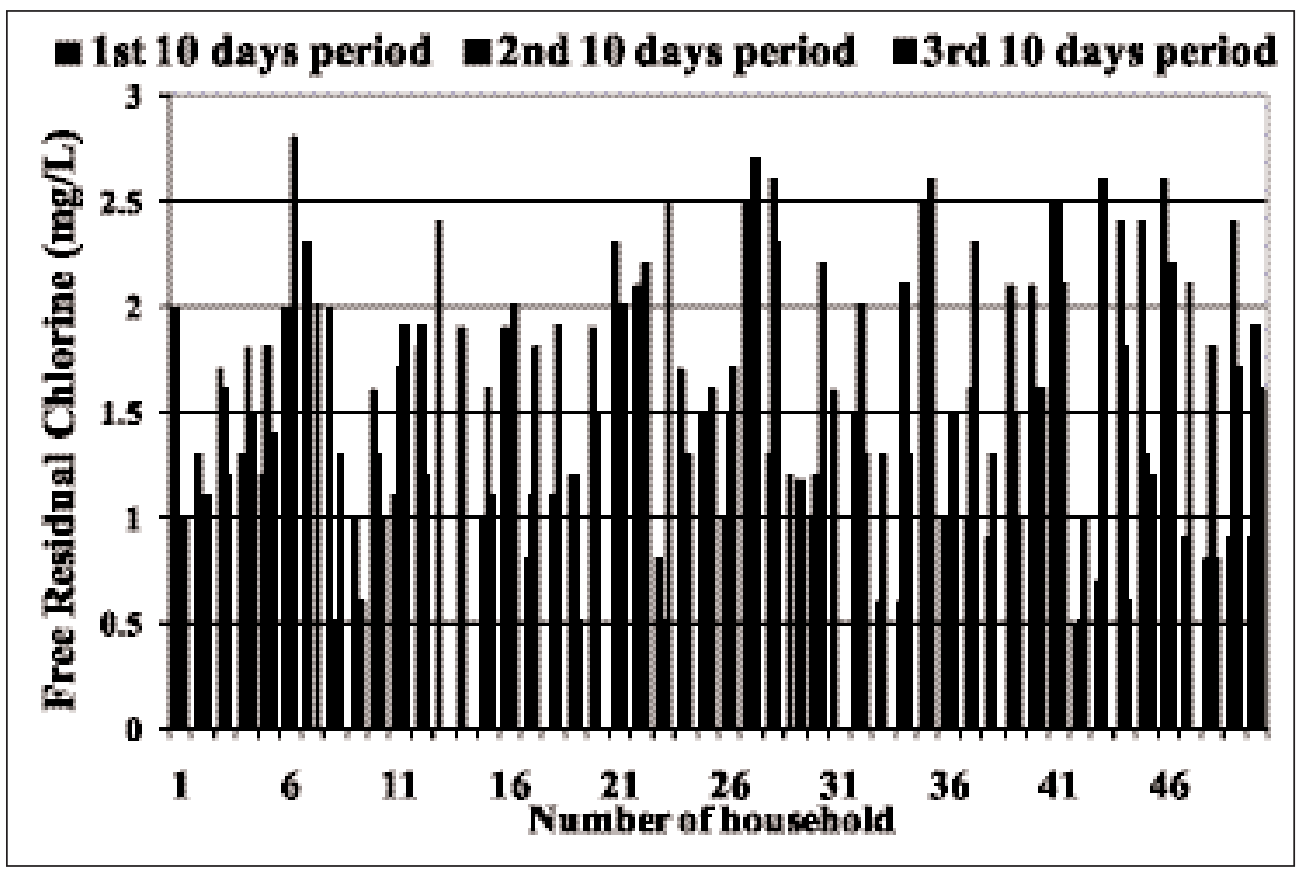

Fig. 4. 10-day period comparison of proper chlorination in surveyed household water in the study area. 
water was under-chlorinated $(<0.5 \mathrm{mg} / \mathrm{L}$ residual free chlorine) the residual chlorine levels ranged from 0.2 to $0.4 \mathrm{mg} / \mathrm{L}$ free residual chlorine. The maximum free residual chlorine level recorded throughout the trial was $2.8 \mathrm{mg} / \mathrm{L}$ free residual chlorine.

\section{Comparison of efficiency of chlorination in all house- holds}

As shown in Figure 5, it was found that during the 1st 10-day period $4 \%$ of households had under-chlorinated and $96 \%$ of households had correctly chlorinated water. At the 2nd 10day period $16 \%$ of households had under-chlorinated and $84 \%$ correctly chlorinated water, while at the 3rd 10-day period $10 \%$ of households had under-chlorinated and $90 \%$ correctly chlorinated water. In this trial study none of the households were found to have over-chlorinated the water. purposes. Their summarized opinion was that "they could not trust on it. God will save them and nothing can happen because of this faecally contaminated water. They used this water for long time and also did not believe that water can cause diarrhoea".

\section{Relationship between successful addition of tablets and incidence of diarrhoea}

In order to show the relationship between successful addition of tablets and incidence of diarrhoeal condition among children under 5 years old, while comparing with the period immediately before (30 days) and after using Aquatabs ${ }^{\mathrm{TM}}$, the total number of children under study was divided into three subgroups as shown below in Table I. Through bacteriological analysis and interviews it became obvious that microbiological water quality was a major factor affecting

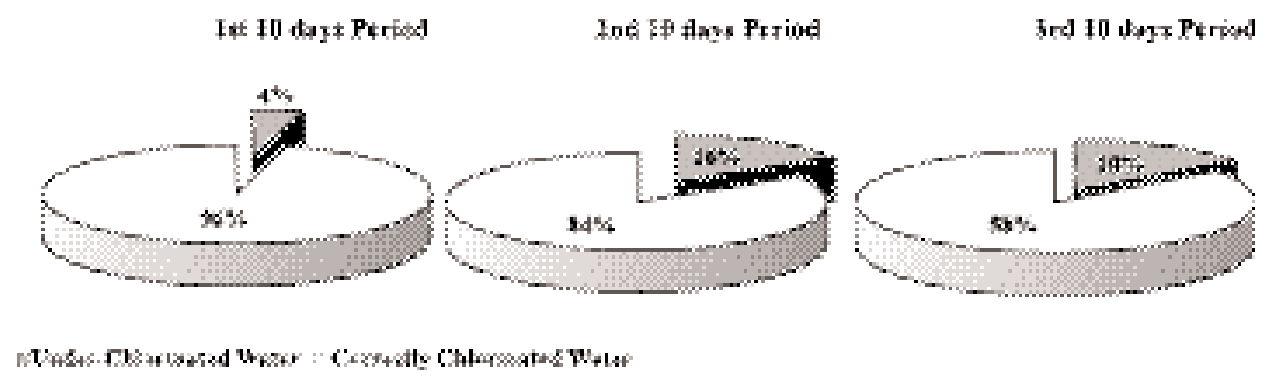

Fig. 5: 10-day period grab samples of efficiency of chlorination of water in all households using Aquatabs

\section{Reasons for non-compliance or drop-out from the study}

In the study area among 50 households only three households had dropped-out from the study. They used Aquatabs over 1st and 2nd 10-day period and at the end of the 3rd 10day period they did not agree to use Aquatabs for drinking health in the study area. Tap water supplied by DWASA, although of a generally good quality, frequently gets contaminated in the poor distribution system through pipe leakage etc, which makes the household water treatment a paramount necessity.

Table I. The relationship between successful application of Aquatabs ${ }^{\mathrm{TM}}$ and incidence of diarrhoeal symptoms

\begin{tabular}{c|c|c|c|c|c}
\hline $\begin{array}{c}\text { Number of } \\
\text { children } \\
\text { under 5 } \\
\text { years old }\end{array}$ & $\begin{array}{c}\text { Diarrhoea } \\
\text { prior to } \\
\text { using } \\
\text { aquatabs }\end{array}$ & $\begin{array}{c}\text { Negative } \\
\text { diarrhoea } \\
\text { group }\end{array}$ & $\begin{array}{c}\text { During trial } \\
\text { minor } \\
\text { diarrhoea } \\
\text { group }\end{array}$ & $\begin{array}{c}\text { Severe } \\
\text { diarrhoea } \\
\text { group }\end{array}$ & $\begin{array}{c}\text { Percentage, } \\
\%\end{array}$ \\
\hline 14 & $\begin{array}{c}\text { Frequent* } \\
\text { Frequent }\end{array}$ & Yes & Yes & Yes & 20.00 \\
10 & $\begin{array}{c}\text { Frequent } \\
\text { Severe }\end{array}$ & & & & 14.3 \\
Total: 70 & & & & 100 \\
\hline
\end{tabular}

* >3 incidences of mild diarrhoea or any serious diarrhoeal conditions 


\section{Conclusion}

The faecal coli forms found may have been due to secondary contamination, there was a strong association between the absence of faecal coli form counts and "correctly chlorinated" water samples $(>0.5 \mathrm{mg} / \mathrm{L}-<5 \mathrm{mg} / \mathrm{L}$ residual free chlorine), the diarrhoea in children $<5$ years of age was reduced from a pre-trial level of $100 \%$ in the "Severe Diarrhoea Group" to $14.3 \%$ during the trial period.

\section{Moreover the findings of the trial were concluded as fol-} lows:

1. It was found through the pre-trial field survey of the local water supply and sanitation, as well as the socioeconomic status in the Lalbagh area, that unsafe drinking water, lack of facilities and unhygienic and unclean domestic environment in the Lalbagh area were the main reasons for the miserable and unhealthy living conditions. Household heads, engaged in informal work activities with low income, are known to be more likely to get sick while children are the most vulnerable to environmental deterioration. Diarrhoea was established to be the most common illness among children under 5 years old (53\% of all illnesses).

2. It transpired that mothers did not use Aquatabs ${ }^{\mathrm{TM}}$ or similar tablets before the survey and treated drinking water by boiling, filtering through cloth etc. They acknowledged that this was very time-consuming. It was also established by the field survey and assumed from high incidence of diarrhoea in the households that this treatment was not effective.

3. Most mothers (78 \%) appreciated Aquatabs ${ }^{\mathrm{TM}}$ and their opinions were found to be:

* the tablets were safe to use and easy to store and handle

* the tablets did not have any smell and odor (some mothers have previously heard that such purification tablets caused bad water smells)

* the tablets did not spread taste of chlorine

* the tablets were effective and dissolved in water quickly

* it was easy to receive and give advice about disinfection by Aquatabs ${ }^{\mathrm{TM}}$ at a household level.

4. Households with correctly chlorinated water showed good correlation with the absence of faecal coli forms, with some exceptions. All under-chlorinated households showed faecal coli forms in their water, with the exception of one result.

5. The results conclusively showed that application of Aquatabs ${ }^{\mathrm{TM}}$ was responsible for a substantial decrease in diarrhoea reported for children under 5 years old. Nearly all the households with under-chlorinated water (free residual chlorine below $0.5 \mathrm{mg} / \mathrm{L}$ ) had increased numbers of reported diarrhoeal symptoms. This observation confirmed critical impact of Aquatabs ${ }^{\mathrm{TM}}$ disinfection.

6. Mothers subjectively appreciated a better and improved general physical state of their children towards the end of the trial period.

7. Most mothers (65 \%) appeared to be willing to pay for Aquatabs $^{\mathrm{TM}}$ in the future. But economic and financial factors are often cited as a constraint to improvement of water quality as well as water supply. They wished that Government and NGOs would help them in getting Aquatabs $^{\mathrm{TM}}$ at household level for drinking water treatment. Though a phenomenon of "willingness to pay" is known to be a fairly deceptive one it still may serve as an indicator of the acceptance of Aquatabs ${ }^{\mathrm{TM}}$ by mothers.

8. However, it was also noted that household heads (fathers) usually were not willing to continue the trial asking "what would be their direct benefit from this trial?" Fortunately, mothers managed to motivate them to utilize Aquatabs ${ }^{\mathrm{TM}}$ disinfecting tablets for a significant period of time.

9. The one month pilot trial project proved high effectiveness of Aquatabs ${ }^{\mathrm{TM}}$ for the treatment of water for human consumption such as drinking and washing.

10. Drinking water treatment with tablets at household level is currently not a common practice in Bangladesh. Large scale application of such tablets would require time to win over the large low-income communities, but would be a good investment in the long-term for health care for the people.

\section{Acknowledgement}

This work was supported by NORAD scholarship, AIT.

\section{References}

APHA (1998) Standard Methods for the Examination of Water and Wastewater. 20th edn. American Public 
Health Association, Washington D.C, pp 29-36.

BBS (2002) Bangladesh Bureau of Statistics. Statistical yearbook of Bangladesh, Population Census 1991, Community series, Zila: Dhaka, pp 56-57.

DPHE. (2003) Annual Progress Report Book 2003, pp 1619.

Hemson David (2001) Closing the Gap? Policy and Practice in Water \& Sanitation, 2001, p.1.

Medentech Ltd. (2004) Aquatabs Technical Report. Wexford, Ireland, 2004, pp 7 -22.

Mollah K. A., and Aramaki T. (2009a) Contribution to Environmental Burdens from Sanitation Systems in Abatement of Health Impacts - case study in low income community of Dhaka, Bangladesh, Southeast Water Environment 3, Takizawa S., Kurisu F. and Satoh H. (eds), IWA publishing, London, UK, Vol. 3, p. 153-158.
Mustafa S. (2008) Diarrhoea Control becomes a social movement in Bangladesh, Diarrhoea control in Bangladesh, Rehydration Project. Available at http://rehydrate.org/diarrhoea/control_in_bangladesh.h tm

UNICEF (2001) Supply Division, Product List, Copenhagen, Denmark. Available at http://www.supply.unicef.dk/catalogue/menu.asp

WHO (2000) United Nations Children's Fund, and Water Supply and Sanitation Collaborative Council, Global Water Supply and Sanitation Assessment 2000 Report.

Received : May, 03, 2009;

Accepted : May, 21, 2009 